\title{
Development of an in Vivo Bioassay Method for Allergy-Preventive Substances Using Hen-Egg White Lysozyme (HEL)-Induced Blood Flow Decrease
}

\author{
Kyoko Ishiguro, * Hisae Oku, Yoshimi Ueda, Emiko Iwaoka, and Masaru Kunitomo \\ School of Pharmaceutical Sciences, Mukogawa Women's University; Koshien Kyuban-cho, Nishinomiya, Hyogo 663-8179, \\ Japan. Received January 20, 2005; accepted May 19, 2005; published online May 26, 2005
}

\begin{abstract}
We discovered a phenomenon in which the blood flow in vein microcirculation markedly decreases in response to hen-egg white lysozyme (HEL)-sensitization without any change in blood pressure. Using this blood flow decrease as a guide, we developed an in vivo assay method to search for substances, which can prevent allergies. Antagonists of histamine, serotonin and platelet activating factor (PAF) did not affect the blood flow decrease in response to HEL-sensitization. On the other hand, cyclooxygenase (COX)-1, COX-2, thromboxane (TX) $A_{2}$, endothelin-1 (ET-1), prostacyclin (PGI $)$ and granulocytic elastase (GE) as well as nitric oxide (NO) from inducible NO synthase (iNOS) were involved in the blood flow decrease. Thus, these substances might injure vascular endothelial cells, and cause a decrease in blood flow in vein microcirculation. Our method can be used to search for preventive agents against allergies involving NO, COX-1, 2 and PGI $_{2}$. This is the first report to applying to an assay method the specific blood flow decrease to occur in the promotion stage of allergy.
\end{abstract}

Key words anti-allergic assay system; blood flow monitoring; hen-egg white lysozyme (HEL); nitric oxide (NO); allergy preventive medicine; microcirculation

Previously, we developed an in vivo assay system for quantitatively estimating mouse hen-egg white lysozyme (HEL)anaphylaxis, including fatal shock. ${ }^{1)}$ This assay system, which uses monitoring of decrease in the blood pressure ${ }^{2)}$ or blood $\mathrm{flow}^{3)}$ in anaphylaxis response, enabled us to study dynamics of anaphylactic response in the same individual animals without killing them. Hence, we elucidated the participation of nitric oxide (NO) in mouse anaphylactic hypotension, ${ }^{4)}$ and the anti-anaphylactic effects of Impatiens balsamina $\mathrm{L}$., from which anti-anaphylactic compounds have been isolated. ${ }^{5,6)}$ We also developed a more rapid assay systems using the blood pressure monitoring system. ${ }^{7-9)}$

Herein, we report that the blood flow of vein microcirculation is markedly decrease by HEL-sensitization alone without the HEL-challenge. There has been no report of the blood flow of vein microcirculation being involved in an initial stage of the immune reaction. The suppression of the blood flow decrease induced by HEL-sensitization may prevent the allergy.

There have been many reports on thrombosis or arteriosclerosis on the microcirculation system of an organ. These finding may have been due to induction by the interaction of NO, prostacyclin $\left(\mathrm{PGI}_{2}\right)^{10)}$ and endothelin-1 (ET1), ${ }^{11-13)}$ although the mechanism has not been clarified yet.

We also investigate the mechanism of the blood flow decrease by the HEL-sensitization, using the inhibitors of chemical mediators and factors involved in the allergy or blood flow. Knowledge of this mechanism should enable us to develop an in vivo assay method to search for anti-allergic substances using the blood flow decrease caused by the HELsensitization.

\section{MATERIALS AND METHODS}

Materials Diphenhydramine hydrochloride (DPH) and L-arginine (L-Arg) were purchased from Nacalai Tesque; 3\{2-[4-(4-fluorobenzoyl)-1-piperidinyl]ethyl $\}-2,4(1 H, 3 H)$ - quinazolinedione tartrate (Ketanserin), ${ }^{14)}$ was from $\mathrm{Fu}$ nakoshi Co., Ltd.; disodium cromoglycate $(\mathrm{DSCG})^{15)}$ was from Molecular Biology Resources, Inc.; rac-3-(N-n-octadecylcarbamoyloxy)-2-methoxy-propyl 2-thiazoliethyl phosphate $(\mathrm{CV}-3988)^{16)}$ was from Biomol Research Laboratories, Inc.; Flurbiprofen and NS-398 ${ }^{17)}$ were from Cayman Co., Ltd.; $N^{\mathrm{G}}$-nitro-L-arginine-methyl-ester (L-NAME) and BQ123 sodium salt ${ }^{18)}$ were from Sigma Co., Ltd.; PGI $_{2}$ derivative (Beraprost sodium) ${ }^{19)}$ was from Yamanouchi Pharmaceutical Co., Ltd.; and (E)-3-[p-(1H-imidazol-1-ylmethyl)-2propenoic phenyl]-acid hydrochloride monohydrate (Ozagrel $\cdot \mathrm{HCl})^{20)}$ was from Ono Pharmaceutical Co. Ltd. $\mathrm{N}-\{2-$ [4-(2,2-Dimethyl propionyloxy)phenylsulfonyl amino]-benzoyl $\}$ aminoacetic acid (ONO-5046 $\cdot \mathrm{Na}$ : Elaspol) ${ }^{21)}$ was a gift from by Ono Pharmaceutical Co. Ltd. (Osaka, Japan). These agents were dissolved in $10 \mu$ l (i.v., s.c., i.p.) or $100 \mu \mathrm{l}$ (p.o.) saline $/ 10 \mathrm{~g}$ body weight.

Animals Male ddY mice (SPF grade), 5 weeks old, were obtained from Japan Shizuoka Laboratory Animal Centre (Shizuoka, Japan) and housed at $24 \pm 2{ }^{\circ} \mathrm{C}$. Food and water were available ad libitum.

HEL Sensitization Immunization with HEL was performed as previously described ${ }^{1)}$ with slight modification. Male ddY mice of 5 weeks of age were sensitized subcutaneously with $50 \mu \mathrm{g}$ of HEL in complete Freund's adjuvant (DIFCO) on day 0.

Blood Flow Measurement Subcutaneous blood flow in the mouse tail was monitored using a Laser Doppler Blood Flow Meter of the non-contact type (FLO-N1, Neuroscience, Japan). Each mouse was pre-warmed for $10 \mathrm{~min}$ at $37^{\circ} \mathrm{C}$, prior to the experiment and was placed on a holder in a measuring chamber kept at $37^{\circ} \mathrm{C}$ throughout the measurement. The systolic blood flow of the venous microcirculation of the tail hypodermic of the unanesthesized mouse was measured $(n=5)$. The normal blood flow was measured for $10 \mathrm{~min}$ at $20 \mathrm{~min}$ before the experiment. The blood flow of sensitized mouse was measured for 10 min every day for $9 \mathrm{~d}$ from the 
sensitization $(0 \mathrm{~d})$ without non-anesthesia. The results were expressed as mean \pm S.E. of the percent of the normal blood flow of each mouse due to large individual differences in blood flow.

Effects of Inhibitors on Blood Flow Decrease of HELSensitized Mice Almost all of the reagents were administered orally $1 \mathrm{~h}$ prior to measurement at 0 (the start day), 3, 6 and $9 \mathrm{~d}$ from the start day of the sensitization using effective quantity and medication methods described in the literature. ${ }^{14-21)}$ Elaspol was administered daily due to its biological instability. None of the reagents affected the blood flow. The measurements of blood flow were carried out almost every day for $9 \mathrm{~d}$. The statistical calculations are shown in comparison with the HEL-sensitized group (the control group).

Natural Whole Blood Clotting Time The whole blood of each sensitized mouse was sampled within $15 \mathrm{~s}$, after the animal was anesthetized with ether on day 9. Natural blood clotting time was measured immediately with an Automatic Blood Coagulometer (Amelung KC 4A). The results are expressed as mean \pm S.E. of the natural blood clotting time for a normal mouse and a sensitized mouse $(n=7)$.

Blood Pressure Measurement Blood pressure and heart rate were measured from the mouse-tail with a BP Monitor MK-2000 (Muromachi Kikai, Tokyo Japan) as previously reported. ${ }^{2)}$ The systolic, mean and diastolic blood pressure was monitored by a computer-controlled photoelectric sensor that detects the appearance and disappearance of the tail arterial pulses against the given cuff pressure. The blood pressure of each mouse was measured for 10 min every day for $9 \mathrm{~d}$ from the sensitization ( 0 day). The blood pressure of normal control mice remained at $90-110 \mathrm{mmHg}$ during a measurement period of $9 \mathrm{~d}$.

NO $x$ Level in Serum Blood was sampled from the mice at 0 (non-treated), 1, 3, 6 and $9 \mathrm{~d}$ after HEL-sensitization. The serum was separated from the blood by centrifugation at $3000 \mathrm{~g}$ for $15 \mathrm{~min}$. The level (concentration) of $\mathrm{NO}_{x}$ $\left(\mathrm{NO}_{2}^{-}+\mathrm{NO}_{3}^{-}\right)$in the serum of mice was determined using $\mathrm{NO}_{2} / \mathrm{NO}_{3}$ assay kit $\mathrm{CII}$ (Dojindo. Lab.) based on the Griess reaction. The serum $\mathrm{NO}_{x}$ level (concentration) was expressed as micromoles per liter $(\mu \mathrm{M})$.

Expression and Amounts of iNOS The expression of inducible NO synthase (iNOS) protein of non-treated and HEL-sensitized mice in the vein of the tail and thoracoabdominal aorta were measured using the Western blot method at $9 \mathrm{~d}$ after sensitization. The X-ray film was scanned into an Adobe Photoshop program (version 3.0) with an Epson scanner (GT-6600U) and transferred to the Macintosh NIH Image program (version 1.61). The density of the bands was measured using NIH Image gel macros. The iNOS protein signals were normalized to the signals of $\alpha$-actin, a specific smooth muscle cell maker. The protein signals obtained were expressed as iNOS/ $\alpha$-actin ration.

Western Blot Analysis The tail vein and thoracoabdominal aorta were homogenized in loading buffer I [0.2 $\mathrm{M}$ Tris$\mathrm{HCl}(\mathrm{pH}=6.8), 1 \mathrm{~mm}$ EDTA, 0.5\% Tween-20, 3\% SDS and $10 \%$ glycerol] and $1 \mu \mathrm{g} / \mu \mathrm{l}$ protease inhibitor cocktail (Sigma) by sonication. The resulting lysate was centrifuged at $9000 \times \mathbf{g}$ for $30 \mathrm{~min}$ at $4{ }^{\circ} \mathrm{C}$ and the supernatant was retained. Protein concentrations were determined using BCA protein assay kit (Pierce Biotechnology Inc.). Electrophoresis was conducted on $17 \mu \mathrm{l}$, which contained $10 \mu \mathrm{g}$ total protein using loading buffer II $(0.2 \mathrm{M}$ Tris- $\mathrm{HCl}(\mathrm{pH}=6.8), 1 \mathrm{~mm}$ EDTA, $0.1 \%$ bromphenol blue, 0.5\% Tween-20, 3\% SDS and $10 \%$ glycerol). The obtained electrophoresis sample was heated at $95^{\circ} \mathrm{C}$ for $5 \mathrm{~min}$ using a heating block after addition of $2 \mu \mathrm{l}$ of $1 \mathrm{~mm}$ dithiothreitol, and electro-separated on $7.5 \%$ SDS-PAGE minigel (Daiichi Pure Chemicals Co. Ltd.) using SDS-Tris-glycine electron buffer at $40 \mathrm{~mA}$, and then electrotransferred to nitrocellulose membrane (Amersham Pharmacia Biotech), which had been dampened using an electroblot buffer kit (Owl Separation System, Inc.) at $100 \mathrm{~mA}$ for $50 \mathrm{~min}$. The membrane was incubated with shaking in $5 \%$ milk in phosphate buffer solution (PBS) for $1 \mathrm{~h}$ at room temperature and then allowed to stand overnight in a refrigerator. The membrane at room temperature was incubated with shaking for $90 \mathrm{~min}$, with anti-iNOS monoclonal antibody (Transdustion Lab.) or anti $\alpha$-actin antibody (Progen) as primary antiboby diluted $1 / 5000$ in $1 \%$ gelatin in wash buffer $(0.1 \%$ Tween-20/PBS). The membrane was washed five times (10 min/washing) with wash buffer and then incubated with shaking for $90 \mathrm{~min}$ at room temperature, with antimouse $\operatorname{IgG}(\mathrm{H}+\mathrm{L})$ as secondary antibody diluted $1 / 2000$ in $1 \%$ gelatin in wash buffer $(0.1 \%$ Tween-20/PBS $)$. The membrane was washed as described previously, and proteins were subsequently subjected to enhanced chemiluminescence (ECL) using the Western blot detection system (Amersham Pharmacia Biotech).

Statistical Analysis Two-way analysis of variance (ANOVA) was used to test for statistical differences. When significant differences $(p<0.05)$ were identified, the data were further analyzed by Dunnett's multiple range test or the Tukey-Kramer test coupled with Bonferroni inequality for significant differences between each test group and the control group. For the Bonferroni test, 5 points were used after day 4 of the HEL-sensitization, because a significance difference was observed between the blood flows of non-treated and sensitized mice after day 4.

\section{RESULTS}

Blood Flow Monitoring of HEL-Sensitized Mice Figure 1 shows the changes in the blood flow for $9 \mathrm{~d}$ from the starting day ( 0 day) of the sensitization. The experiment was repeated 5 times at $n=5$. The blood flow of HEL-sensitized mice significantly decreased gradually to $65-75 \%$ of the blood flow of normal mice at day 9 with good reproducibility. However, the heart rate and systolic, mean and diastolic blood pressure of sensitized mice were almost the same as the values for normal mice for $9 \mathrm{~d}$ (Fig. 2). The results suggest that peripheral venous constriction and blood viscosity relate to the blood flow decrease; support for this came from the significant shortening of the blood clotting time in HELsensitized mice at day 9 in comparison with the normal mice as shown in Fig. 3. The production of the $\operatorname{IgE}$ antibody has been reported to increase after day 6 of the HEL-sensitization. ${ }^{1)}$

These results indicate that the monitoring system could be utilized as an assay method to search for substances that suppress the blood flow decrease.

Mechanism of Blood Flow Decrease in Response to HEL-Sensitization The following reagents were used with 
HEL-sensitized mice to elucidate of the mechanism of the blood flow decrease.

1. Effect of Chemical Mediator-Related Agents: DSCG, Ketanserin, DPH and CV-3988 are currently used as anti-allergic agents (Figs. $4 \mathrm{~A}-\mathrm{C}$ ).

DSCG: DSCG $(10 \mathrm{mg} / \mathrm{kg}$, i.v. $)$, a degranulation depressant agent, ${ }^{15)}$ significantly inhibited the blood flow decrease com-

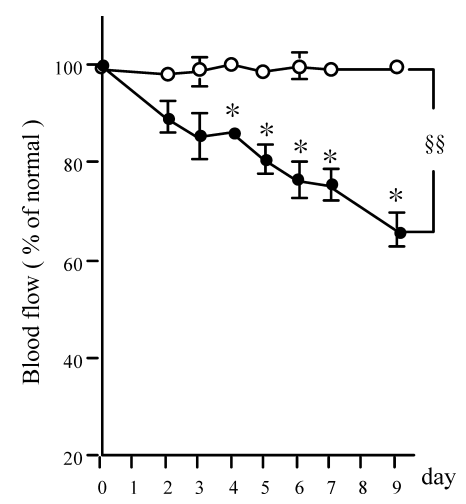

Fig. 1. Change of Blood Flow in the Mouse Tail Vein after HEL-Sensitization

$\bigcirc$ : Nontreatment normal mice; 0 : HEL-sensitized mice. Results are the means \pm S.E. for 5 mice. $* p<0.05, * * p<0.01$ as compared with normal group (Dunnett's test with Bonferroni). $\$$ indicates $p<0.01$ (two-way ANOVA).
(A)

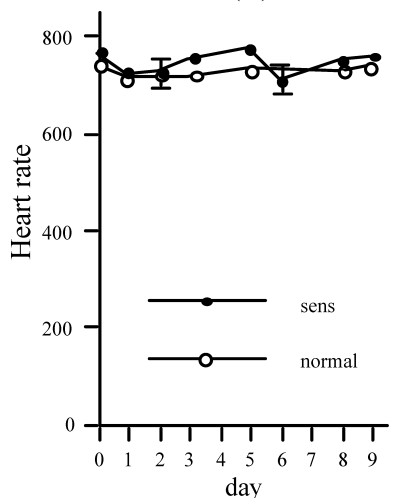

(B)

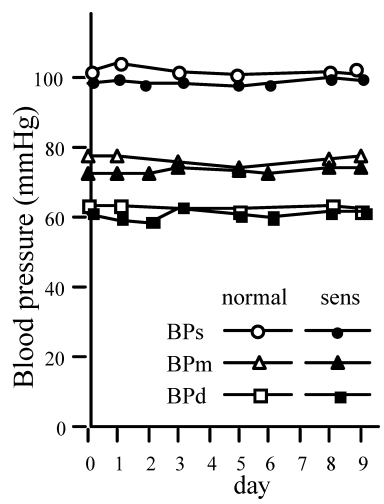

Fig. 2. The Heart Rates and Blood Pressures (BP) of Sensitized Mice and Normal Mice

(A) Heart rates; $\bigcirc$ : normal (nontreatment normal mice); $\bullet$ : sens. (HEL-sensitized mice). (B) blood pressure of systoic (BPs), mean (BPm) and diastolic (BPd); $\bigcirc, \triangle, \square$ : normal; $\boldsymbol{\bullet}, \boldsymbol{\Delta}, \mathbf{\square}$ : sens. $(n=5)$. (Dunnett's test with Bonferroni). pared with the control group after day 4 of sensitization (Fig. 4A). This suggested that IgE-mediated substances are related to the HEL-induced blood flow decrease.

Ketanserin: Ketanserin $(10 \mathrm{mg} / \mathrm{kg}$, i.v.), an antagonist of serotonin $5 \mathrm{HT}_{2 \mathrm{~A}}$ receptor $^{14)}$ is related to platelet aggregation and vasoconstriction. However, ketanserin did not suppress the blood flow decrease (Fig. 4B). Thus, serotonin dose not seem to be related to the HEL-induced blood flow decrease.

DPH: DPH $(10 \mathrm{mg} / \mathrm{kg}$, p.o. $)$, an antagonist of histamine $\mathrm{H}_{1}$ receptor, did not suppress the blood flow decrease (Fig. 4B). Thus, histamine would not involve in the HEL-induced blood flow decrease.

CV-3988: CV-3988 is an antagonistic agent ${ }^{16)}$ of platelet activating factor (PAF) which is known as a chemical mediator of allergic and inflammatory reactions. PAF has a potent and wide variety of biological actions: stimulation of platelets and leukocytes, bronchoconstriction, hypotension, depression of cardiac function and increase in vascular permeability. ${ }^{22)}$ There have been reports of a lethal role of PAF in bovine serum albumin-induced anaphylactic shock in mice ${ }^{23)}$ and on the effect of decreasing blood pressure in endotoxin shock of rats. ${ }^{24)}$ Our previous findings also suggested that PAF acts as a primary initiator of HEL-induced anaphylactic hypotension in a manner similar to histamine. $\left.{ }^{6}\right)$ However, CV-3988 (10 mg/kg, i.v.) hardly suppressed the blood flow decrease (Fig. 4C). This suggested that PAF affects a different stage of anaphylaxis.

2. Effect of Granulocytic Elastase (GE) Inhibitor: GE is an enzyme released from activated neutrophil, which en-

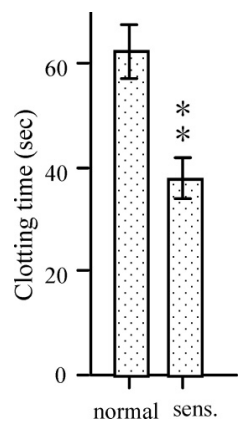

Fig. 3. Blood Clotting Time of HEL-Sensitized Mice

Normal: nontreated normal mice; sens.: HEL-sensitized mice. Results are the means \pm S.E. for 7 mice. $* * p<0.01$ compared with normal by Student's $t$-test.
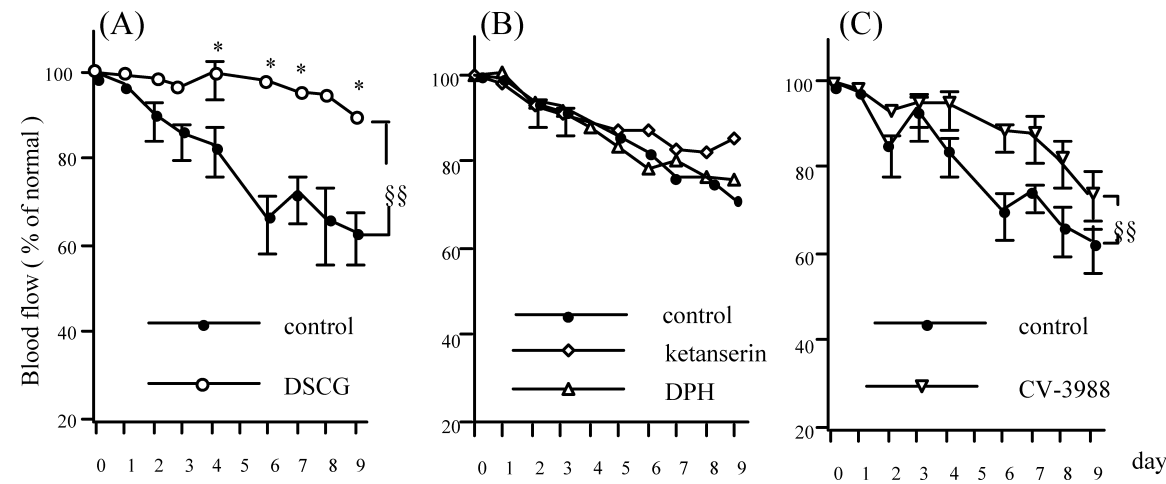

Fig. 4. Effect of Chemical Mediators by HEL-Sensitization

๑: control (blood flow of HEL-sensitized mice), (A); $\bigcirc$ : pretreatment with DSCG, (B); $\diamond$ : pretreatment with ketanserin; $\triangle$ : pretreatment with DPH, (C); $\nabla$ : pretreatment with $\mathrm{CV}-3988$ at $1 \mathrm{~h}$ prior to measurement at 0 (the start day), 3, 6 and $9 \mathrm{~d}$ from the sensitization. Each value presents the mean \pm S.E. $(n=5)$. $* p<0.05$ as compared with control group (Dunnett's test with Bonferroni). Parenthesis line with $\$$ indicates $p<0.01$ (two-way ANOVA). 

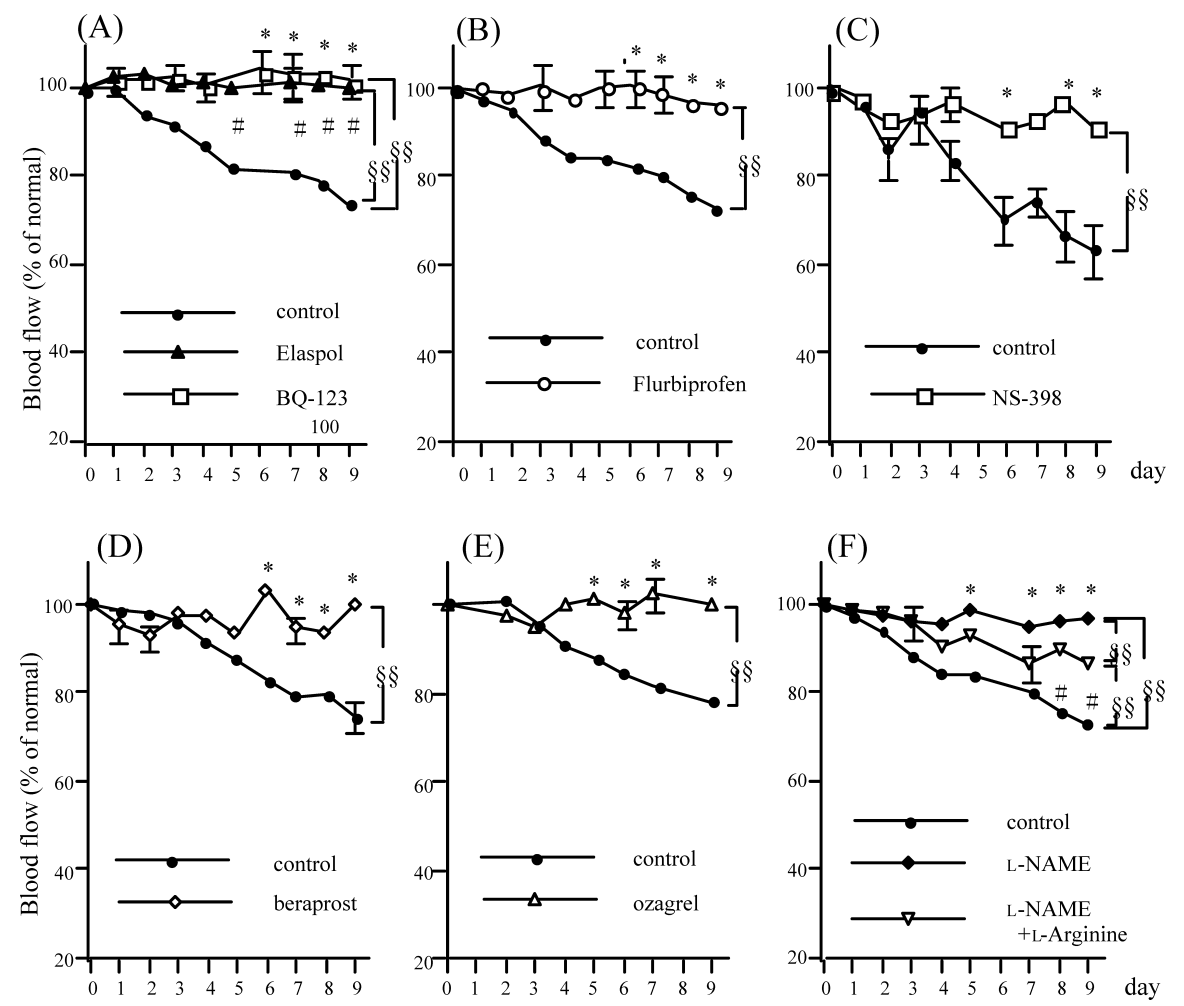

Fig. 5. The Effect of Granulocytic Elastase and Vascular Endothelial Cell Derived Materials

: control (blood flow of HEL-sensitized mice), (A); $\triangle$ : pretreatment with elaspol; $\square$ : pretreatment with BQ-123, (B); $\bigcirc$ : pretreatment with flurbiprofen, (C); $\square$ : pretreatment with NS-398, (D); $\diamond$ : pretreatment with beraprost, (E); $\triangle$ : pretreatment with ozagrel, (F); $\nabla$ : pretreatment with L-NAME, (G); $\bullet$ pretreatment with L-NAME and L-arginine (L$\mathrm{Arg}$ ), at $1 \mathrm{~h}$ prior to measurement at 0 (the start day), 3,6 and $9 \mathrm{~d}$ from the sensitization. Each value presents the mean \pm S.E. $(n=5$ ). $\$ \$$ indicates $p<0.01$ (two-way ANOVA). * and $\# p<0.05$ as compared with control group (A-E: Dunnett's test with Bonferroni, F: Tukey's test with Bonferroni).

hances vascular permeability and injures vascular endothelial cells. $^{25)}$

Elaspol: Elaspol ${ }^{21)}(100 \mathrm{mg} / \mathrm{kg}$, s.c.), a selective GE inhibitor, significantly inhibited the blood flow decrease, compared with the control group after day 5 of the HEL-sensitization (Fig. 5A). Thus, the activation of neutrophils would also affect the blood flow decrease.

3. Effect of Vasoactive Materials: Vascular endothelial cells are deeply involved in the maintenance of smooth microcirculation and blood vessel tension, local inflammation and blood coagulation. $\mathrm{PGI}_{2}$ and thromboxane (TX) $\mathrm{A}_{2}$, produced by cyclooxygenase ( $\mathrm{COX}$ ) in vascular endothelial cells and platelets, respectively, show contradictory actions against thrombocyte and vascular smooth muscle, and thus, the homeostasis of platelets is balanced by these two mediators. $^{26)}$ ET-1 is a vasoconstrictor, released from vascular endothelial cells by the stimulation of inflammatory cytokines and blood coagulation factors. ${ }^{27,28)}$ When vascular endothelial cells are injured via neutrophils resulting from various types of shock, invasion of xenobiotics or systemic organ failure, the production of $\mathrm{NO}$ and $\mathrm{PGI}_{2}$ would be inhibited and thus the vasoconstrictor action by ET-1 would become relatively predominant. Consequently, microcirculation failure would be induced. ${ }^{29)}$

Flurbiprofen: Flurbiprofen is a selective COX-1 inhibitor. $^{30)}$ COX-1 works not only in the defense for a rapid physiological change in circulatory organs, but also induces the production of $\mathrm{TXA}_{2}$, followed by platelet aggregation in hematoblasts. $^{31)}$ Flurbiprofen $(10 \mathrm{mg} / \mathrm{kg}$, p.o. $)$ significantly inhibited the blood flow decrease, compared with the control group after day 6 of the HEL-sensitization (Fig. 5B). Thus, platelet aggregation by COX-1 may be involved in the blood flow decrease.

NS-398: NS-398 ${ }^{17)}$ is a selective COX-2 inhibitor. The production of COX-2 is generally induced in vascular endothelial cells by inflammatory stimulation, followed by the production of various $\mathrm{PGs}$ such as $\mathrm{PGI}_{2}$, which leads to venous vasodilation and improvement of the blood flow. NS398 (3 mg/kg, i.p.) significantly inhibited the blood flow decrease compared with the control group after day 6 of HELsensitization (Fig. 5C). This result seems to contradict the function of inductive $\mathrm{COX}-2$. However, since constitutive COX-1 would compensate for the function of inductive COX-2 to maintain homeostasis, ${ }^{32)}$ the blocking of COX-2 by NS-398 might induce the COX-2 function in COX-1.

Beraprost: Beraprost sodium ${ }^{19)}(40 \mu \mathrm{g} / \mathrm{kg}$, p.o. $)$, a stable analog of $\mathrm{PGI}_{2}$, significantly inhibited the blood flow decrease compared with the control group after day 6 of the HEL-sensitization (Fig. 5D). This result suggests that the reduction of $\mathrm{PGI}_{2}$ production, consequently the vasoconstriction accompanies the blood flow decrease due to the sensitization.

Ozagrel: Ozagrel $^{20)}$ is a specific synthase inhibitor of $\mathrm{TXA}_{2}$, which is an arachidonic acid metabolite, and causes platelet aggregation. Ozagrel $(300 \mathrm{mg} / \mathrm{kg}$, p.o.) significantly inhibited the blood flow decrease after day 5 of the HEL-sensitization (Fig. 5E). This finding suggests that $\mathrm{TXA}_{2}$ is involve in the blood flow decrease due to the sensitization.

BQ-123: BQ-123 ${ }^{18}$ is a selective inhibitor of ET-1. BQ123 (1 mg/kg, i.v.) significantly inhibited the blood flow de- 


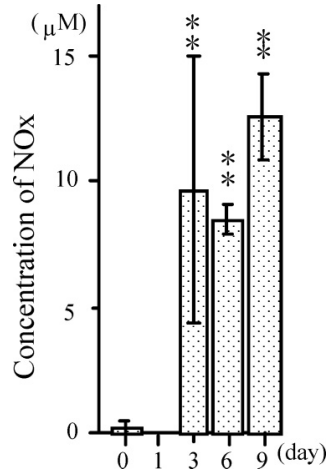

Fig. 6. Change in $\mathrm{NO}_{x}$ Level by Sensitization

Concentration of $\mathrm{NO}_{x}\left(\mathrm{NO}_{2}^{-}+\mathrm{NO}_{3}^{-}\right)$in the serum of mice at 0 (non-treated), 1, 3, 6 and $9 \mathrm{~d}$ after HEL-sensitization. The results are expressed as the mean \pm S.E. $(\mu \mathrm{M})$ and are evaluated by Dunnett's test ( $n=3$ per group). $* * p<0.01$ versus day 0 group.

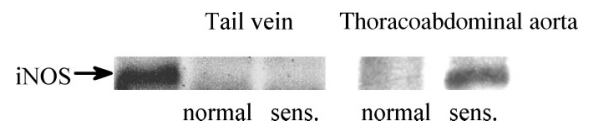

Fig. 7. Western Blot Analysis of iNOS in HEL-Sensitized Mice

The expression iNOS protein of non-treated (normal) and HEL-sensitized (sens.) mice in the tail vein and thoracoabdominal aorta were determined at $9 \mathrm{~d}$ after sensitization.

crease compared with the control group after day 6 of the sensitization (Fig. 5A). This result indicates that the vasoconstriction by ET-1 is involved in the blood flow decrease.

4. Relationship with NO: NO is widely known to improve blood flow in circulatory organs and decrease blood pressure by its vasodilator action.

Effect of L-NAME and L-Arg: L-NAME (10 mg/kg, i.p.), a NO synthase inhibitor, significantly inhibited the blood flow decrease compared with the control group after day 5 of sensitization. When L-Arg $(600 \mathrm{mg} / \mathrm{kg}$, i.p. $)$, a biosynthetic precursor of NO, was administered together with L-NAME, the recovery rate of the blood flow decrease was significantly less than L-NAME alone (Fig. 5F). These results indicate that $\mathrm{NO}$ is involved in the blood flow decrease.

NO also modulates the permeability of microvascular endothelial cells. ${ }^{33)}$ Thus, the inhibition of NO synthase provokes a decrease of capillary water permeability, leading to a decrease in blood viscosity. Furthermore, in the defense against infection, NO, superfluously created by iNOS, reacts with superoxide $\left(\mathrm{O}_{2}^{-}\right)$, and produces peroxynitrate $\left(\mathrm{ONOO}^{-}\right)$, which antagonizes NO. These mutually opposing activities have been referred to as a dichotomy of NO action. ${ }^{34)}$ Thus, L-NAME seems to improve blood flow by suppressing antiinflammatory action and the increase in blood viscosity caused by NO.

Change in NO Production by HEL-Sensitization The amount of $\mathrm{NO}_{x}\left(\mathrm{NO}_{2}^{-}+\mathrm{NO}_{3}^{-}\right)$production in blood after the sensitization was measured by the Griess method. ${ }^{35)}$ The $\mathrm{NO}_{x}$ quantity in the serum increased synchronously with the blood flow decrease after day 3 of sensitization (Fig. 6).

Expression of iNOS by the HEL-Sensitization iNOS was induced by inflammation or allergy. The iNOS expression in sensitized mice was measured at day 9 by the western blot method. The expression of iNOS was observed in the thoracoabdominal aorta, while iNOS was not expressed in the tail vein where the blood flow was measured as shown in
Fig 7. In the non-treated group, iNOS was not expressed in either position. These results indicate that the expression of iNOS is induced in the large artery but not in the vein by the sensitization.

\section{DISCUSSION}

In this study, we developed a new in vivo assay method for screening of anti-allergy substances. That was established by monitoring the blood flow in the tail vein of HEL-sensitized mice, which gradually and reproducibly decreased the blood flow to about $65-75 \%$ of that of normal mice up to 9 th day. The blood flow could be dynamically and easily measured by using the laser Doppler blood flow meter. We termed this phenomenon the promotion (afferent) stage of the allergy progressed by xenobiotics, because it appeared without readministration of HEL that develops anaphylaxis.

This blood flow decrease appears to be due to contraction of peripheral veins and increase in blood viscosity, because no relationship with blood pressure was observed. The blood flow decrease would be involved in the development of more serious forms ( $c a$. 80\% mortality) of anaphylaxis, which have been previously reported. ${ }^{1-3)}$

The mechanism of the blood flow decrease is very complicated and is hard to explain at present, but we assume the following process. NO generated by eNOS in vascular endothelial cells maintains the blood flow by controlling vascular tonus. After the sensitization, (i) cytokines induced by HEL activate neucleophils which released GE. (ii) Injury of vascular endothelial cells by GE would inhibit the production of $\mathrm{NO}$ and $\mathrm{PGI}_{2}$. As the result, the relatively predominant ET-1 induces microcirculation failure, followed by blood flow decrease. (iii) The resulting ischemia would facilitate the production of cytokines, which induces the expression of COX-2 and iNOS. However, this hypothesis is contradictory to the fact that L-NAME inhibited the decreased blood flow induced by HEL-sensitization. We need to further investigate the contradiction. This mechanism is similar to that in disseminated intravascular coagulation (DIC) ${ }^{36)}$ and thus would be worthy of further examinations.

The present results suggested that measurement of the blood flow decrease can be utilized for an in vivo assay method for the search of agents that can prevent allergies. The present research on allergy by blood flow monitoring can also be applied to the development of preventive medicines for thrombosis, which requires multi-target inhibitory activities to serve as a remedy. Our method should be useful for the search for anti-allergic agents.

Now, we are examining the more detailed mechanism using iNOS knockout mouse how iNOS and COX to be concerned in the blood flow decrease. The result will be report in due course together with the application of this assay method.

Acknowledgements The authors are grateful to Prof. Dr. Masanori Semma and associate prof. Dr. Sumio Matuno of Mukogawa Women's University for their useful suggestions. We also thank to Ono Pharmaceutical Co. Ltd. for providing Eraspol. This work was supported in part by a Grant-in-Aid for Scientific Research (C) from the Ministry of Education, Culture, Sports, Science and Technology, Japan. 


\section{REFERENCES}

1) Ishiguro K., Fukumoto H., Murashima T., Kuriyama M., Semma M., Isoi K., Phytother. Res., 6, 112-113 (1992).

2) Ishiguro K., Fukumoto H., Osada S., Isoi K., Semma M., Phytother. Res., 8, 301-304 (1994).

3) Ishiguro K., Ohira Y., Oku H., Biol. Pharm., Bull., 25, 505-508 (2002).

4) Osada S., Ichiki H., Oku H., Ishiguro K., Kunitomo M., Semma M., Eur. J. Pharmacol., 252, 347-350 (1994).

5) Fukumoto H., Yamaki M., Isoi K., Ishiguro K., Phytother. Res., 10, 202-206 (1996).

6) Fukumoto H., Ishiguro K., Phytother. Res., 11, 48-50 (1997).

7) Fukumoto H., Isoi K., Semma M., Ishiguro K., Phytother. Res., 9, $567-570$ (1995)

8) Oku H., Ishiguro K., Phytother. Res., 13, 521-525 (1999).

9) Ueda Y., Oku H., Iinuma M., Ishiguro K., Biol. Pharm. Bull., 26, 1505-1507 (2003).

10) Bokoch G., Blood, 86, 1649-1660 (1995).

11) LeRoy E. C., Ager A., Gordon J. L., J. Clin. Invest., 74, 1003-1010 (1984).

12) Denucci G., Thomas R., D’Orleans-Juste P., Antunes E., Walder C., Warner T. D., Vane J. R., Proc. Natl. Acad. Sci. U.S.A., 85, 97979800 (1988).

13) Zuccarello M., Romano A., Passalacqa M., Am. J. Physiol., 269, H1009-H1015 (1995).

14) Leysen J. E., Awouters F., Kennis L., Laduron P. M., Vandenberk J., Janssen P. A., Life Sci., 28, 1015-1022 (1981).

15) Terashita Z., Imura Y., Takatani M., Tsushima S., Nishikawa K., J. Pharmacol. Exp. Ther, 242, 263-268 (1987).

16) Terashita Z., Tsushima S., Yoshioka Y., Nomura H., Inada Y., Nishikawa K., Life Sci., 32, 1975-1982 (1983).

17) Tsugawa K., Hashizume M., Migou S., Kishihara F., Kawanaka H., Tomikawa M., Sugimachi K., J. Gastroenterol Hepatol., 14, 642-651 (1999).
18) Ihara M., Noguchi K., Saeki T., Fukuroda T., Tsuchida S., Kimura S., Fukami T., Ishikawa K., Nishikibe M., Yano M., Life Sci., 50, 247255 (1992).

19) Kainoh M., Maruyama I., Nishio S., Nakadate T., Biochem. Pharmacol., 41, 1135-1140 (1991).

20) Kikuchi S., Takehana Y., Ichikawa K., Komatsu H., Okegawa T., Ikeda S., Nippon Yakurigaku Zasshi, 95, 131-137 (1990).

21) Pradella L., Current Opinion in Anti-inflammatory and Immunomodulatory Investigational Drugs, 1, 485-501 (1999).

22) Hanahan D. J., Annu. Rev. Biochem., 55, 483-509 (1986).

23) Terashita T., Imura Y., Shino A., Nishikawa K., J. Pharmacol. Exp. Ther, 243, 378-383 (1987).

24) Terashita T., Imura Y., Nishikawa K., Sumida S., Eur. J. Pharmacol., 109, 257-261(1985).

25) Suttorp N, Olte A., Wilkw A., Int. J. Microcirc., 13, 187-203 (1993).

26) Galie N., Manes A., Branzi A., Am. J. Respir. Med., 2, 123-137 (2003).

27) Yanagisawa M., Kurihara H., Kimura S., Nature (London), 332, 411415 (1988).

28) Haller H., Drugs, 53, 1-10 (1997).

29) Filep J.-G., Battistini B., Cote Y., Beaudoin R.-A., Sirois P., Biochem. Biophys. Res. Commun., 177, 171-177 (1991).

30) Cryer B., Feldman M., Am. J. Med., 104, 413-421 (1998).

31) Cheng Y., Austin S. C., Rocca B., Koller B. H., Coffman T. M., Grosser T., Lawson J. A., FitzGerald G. A., Science, 296, 539—541 (2002).

32) Kirtikara K., Morham S. G., Raghow R., Laulederkind S. J. F., Kanekura T., Goorha S., Ballou L. R., J. Exp. Med., 187, 517—523 (1998).

33) Rumbaut E.-R., Mckay K.-M., Huxley H.-V., Amer. Physiol. Soc., 1856-1861 (1995).

34) Akaike T., Suga M., Maeda H., Proc. Soc. Exp. Biol. Med., 217, 6473 (1998).

35) Archer S., FASEB J., 7, 349-360 (1993).

36) Bick R.-L., Arun B., Frenkel E.-P., Haemostasis, 29, 111-134 (1999). 